\title{
Oncogenic miR-425-5p is associated with cellular migration, proliferation and apoptosis in renal cell carcinoma
}

\author{
JING QUAN ${ }^{1-3 *}$, YAWEN LI $^{1-3^{*}}$, XIANG PAN ${ }^{1-3}$, YULIN LAI $^{1,3}$, TAO HE $^{1,3}$, CANBIN LIN $^{1,3}$, \\ LIANG ZHOU ${ }^{1,3}$, LIWEN ZHAO ${ }^{1-3}$, SHUOLEI SUN ${ }^{1}$, YU DING $^{1}$, LINGZHI TAO ${ }^{1}$, YIMIN HU ${ }^{1}$, \\ XIONGHUI WU ${ }^{1}$, ZEBO CHEN $^{1}$, FANGTING ZHANG ${ }^{3}$, JING YE ${ }^{3}$, \\ LIANGCHAO NI $^{1}$ and YONGQING LAI ${ }^{1,3}$ \\ ${ }^{1}$ Department of Urology, Peking University Shenzhen Hospital, Shenzhen, Guangdong 518036; \\ ${ }^{2}$ Department of Urology, Anhui Medical University, Hefei, Anhui 230032; ${ }^{3}$ The Guangdong and \\ Shenzhen Key Laboratory of Male Reproductive Medicine and Genetics, Peking University Shenzhen Hospital, \\ Institute of Urology of Shenzhen PKU-HKUST Medical Center, Shenzhen, Guangdong 518036, P.R. China
}

Received July 28, 2017; Accepted April 20, 2018

DOI: $10.3892 / 01.2018 .8948$

\begin{abstract}
An increasing number of studies have demonstrated the function of microRNAs (miRNAs) in the initiation and development of various types of cancer. Among them, miR-425-5p is proven to serve an important function in several types of cancer, including gastric, cervical cancer, and hepatocellular carcinoma. However, the function of miR-425-5p in renal cell carcinoma (RCC) remains unclear. In the present study, it was demonstrated that the expression level of miR-425-5p was upregulated in RCC tissues and cell lines compared with normal tissues and cell lines $(\mathrm{P}<0.05)$. Additionally, Cell Counting kit-8 and MTT assays were employed to assess cell viability and proliferation, whereas wound healing and Transwell assays were employed to examine migration and invasion. The results demonstrated that upregulation of miR-425-5p promoted cell viability and the invasion and migration of ACHN and 7860 cells $(\mathrm{P}<0.05)$. Flow cytometric analysis confirmed that upregulation of miR-425-5p inhibited apoptosis of ACHN and 7860 cells $(\mathrm{P}<0.05)$. Downregulation of miR-425-5p inhibited the viability and invasion and migration of ACHN and 7860 cells $(\mathrm{P}<0.05)$. In the present study, upregulation of miR-425-5p inhibited apoptosis of ACHN and 7860 cells whereas no differences in early apoptotic rate were observed between the inhibitor and inhibitor $\mathrm{NC}$ groups for $786 \mathrm{O}$ and $\mathrm{ACHN}$
\end{abstract}

Correspondence to: Professor Yongqing Lai, Department of Urology, Peking University Shenzhen Hospital, 1120 Lianhua Road, Shenzhen, Guangdong 518036, P.R. China

E-mail: yqlord@163.com

*Contributed equally

Key words: microRNA, microRNA-425-5p, renal cell carcinoma, oncogene cells. These results indicate that miR-425-5p may act as an oncogene in RCC.

\section{Introduction}

Renal cell carcinoma ( $\mathrm{RCC}$ ) is the most common tumor arising in the kidney and accounts for 2-3\% cases among all types of cancer. In western countries, RCC has risen by $\sim 2 \%$ during the last two decades (1). An epidemiology study indicated that RCC (particularly clear cell RCC) exhibits a moderate male predilection (2). Previous studies demonstrated that the occurrence, development and prognosis of RCC are associated with specific genes, including von Hippel-Lindau tumor suppressor (3) and polybromo-1 (4).

MicroRNAs (miRNAs/miRs) are a class of conservative and small non-coding RNAs, which negatively regulate the expression level of target genes by binding to sequences in 3'-untranslated regions (5). Previous studies indicated that miRNAs are implicated in the recurrence, development and prognosis of various types of cancer. Several miRNAs may be deregulated in RCC. For example, miR-15a was significantly downregulated in RCC tissues compared with adjacent normal tissues (6). Furthermore, Li et al (6) demonstrated that the downregulation of miR-15a may suppress cell proliferation and invasion by directly targeting eukaryotic initiation factor 4E during RCC progression. Additionally, miR-149-5p may act as a tumor suppressor in cellular migration, invasion and apoptosis in RCC, whereas miR-142-3p may serve an oncogenic function $(7,8)$.

miR-425-5p is located on human chromosome 3 and is aberrantly expressed in various types of cancer, including gastric (9), cervical (10) and hepatocellular carcinoma (11). Reverse transcription quantitative polymerase chain reaction (RT-qPCR) analysis indicated an overexpression of miR-425-5p in RCC tissues, thus suggesting its potential use as a biomarker for the diagnosis of RCC $(12,13)$. However, the molecular mechanisms underlying the effects miR-425-5p in RCC remain to be elucidated. In the present study, not only 
the expression of miR-425-5p was detected in RCC tissues and cell lines but also the function of miR-425-5p was investigated in RCC cell lines in vitro.

\section{Materials and methods}

Specimens. A total of 24 paired RCC and adjacent normal tissue specimens (5 $\mathrm{cm}$ distance from the tumor margin) were obtained from the Department of Urology, Peking University Shenzhen Hospital (Shenzen, China) between January 2013 and December 2013. The patients that were recruited to the study met the following main conditions: i) Men or women with age between 18-75 and diagnosis of renal cell carcinoma by pathology; ii) normal function of the main organs; iii) subjects volunteered to join the study, signed the informed consent form, had good compliance and cooperated with the follow-up; iv) no history of other malignant tumors, and serious, uncontrolled concomitant diseases that may affect the compliance to the study or interfere with the interpretation of the results of in the past 5 years. Patients were excluded when participation in the study was likely to be associated with a greater risk to the patient, and when other severe illnesses or laboratory abnormalities that could interfere with the interpretation of the results of the study were apparent.

After surgery, all specimens were immersed in RNAlater ${ }^{\circledR}$ RNA Stabilization Reagent (Qiagen $\mathrm{GmbH}$, Hilden, Germany) and stored at $-80^{\circ} \mathrm{C}$. All patients signed written informed consent. The study was approved by the Ethics Committee of Peking University Shenzhen Hospital. The clinicopathological features of patients are presented in Table I $(14,15)$.

$R T-q P C R$. Total RNA was isolated from tissues using TRIzol reagent (Thermo Fisher Scientific, Inc., Waltham, MA, USA), according to the manufacturer's instructions. RNA was purified using RNeasy Maxi kit (Qiagen GmbH). The concentration of RNA was measured using a NanoDrop 2000c spectrophotometer (Thermo Fisher Scientific, Inc.). RNA was reverse-transcribed into cDNA using a miScriptII RT kit (Qiagen $\mathrm{GmbH}$ ), according to the manufacturer's instructions. qPCR was performed using miScript SYBR-Green PCR kit (Qiagen $\mathrm{GmbH}$ ) and the Roche LightCycler 480 Real-Time PCR System (Roche Diagnostics GmbH, Mannheim, Germany), according to the manufacturer's instructions. The thermocycling conditions were as follows: Initial activation step at $95^{\circ} \mathrm{C}$ for $15 \mathrm{~min}$, followed by 40 cycles, denaturation at $94^{\circ} \mathrm{C}$ for $15 \mathrm{sec}$, annealing at $55^{\circ} \mathrm{C}$ for $30 \mathrm{sec}$ and extension at $72^{\circ} \mathrm{C}$ for $30 \mathrm{sec}$. U6 was used as an internal control. Relative expression values were calculated using the $2^{-\Delta \Delta \mathrm{Cq}}$ method (16).

Cell culture. HK2 and RCC (ACHN, 7860, Caki-1 and 769P) cell lines were obtained from the Guangdong and Shenzhen Key Laboratory of Male Reproductive Medicine and Genetics (Shenzhen, China). ACHN cells were cultured in Dulbecco's modified Eagle's medium (DMEM; Thermo Fisher Scientific, Inc.). 786-O and 769P cells were cultured in RPMI-1640 medium (Thermo Fisher Scientific, Inc.). Caki-1 cells were cultured in McCoy's 5A modified medium
Table I. Clinicopathological characteristics of patients with renal cell carcinoma.

\begin{tabular}{lc}
\hline Characteristics & Patients, $\mathrm{n}$ \\
\hline Age, years & \\
Mean & 51 \\
Range & $27-72$ \\
Sex & \\
Male & 18 \\
Female & 6 \\
Histological type & \\
Clear cell & 20 \\
Papillary & 4 \\
Fuhrman grade (14) & \\
I & 15 \\
II & 7 \\
III & 1 \\
IV & 1 \\
AJCC clinical stage (15) & \\
I & 15 \\
II & 8 \\
III+IV & 1 \\
\hline
\end{tabular}

Table II. Concentration of the miRNA mimic/inhibitors used for transfection.

\begin{tabular}{lccc}
\hline Plate & siRNA, $\mu 1$ & $\begin{array}{c}\text { Final } \\
\text { volume, } \mu 1\end{array}$ & $\begin{array}{c}\text { Lipofectamine } \\
\text { 2000, } \mu 1\end{array}$ \\
\hline 96-well & $0.5(5 \mathrm{pmol})$ & 100 & 0.25 \\
24-well & $1(20 \mathrm{pmol})$ & 500 & 1 \\
12-well & $2(40 \mathrm{pmol})$ & 1,000 & 2 \\
6-well & $5(100 \mathrm{pmol})$ & 2,000 & 5 \\
\hline
\end{tabular}

siRNA, small interfering RNA.

(Thermo Fisher Scientific, Inc.). Cells were grown in media supplemented with $10 \%$ fetal bovine serum (FBS; Gibco; Thermo Fisher Scientific, Inc.), $1 \%$ glutamine and $1 \%$ antibiotics $(100 \mathrm{U} / \mathrm{ml}$ penicillin and $100 \mathrm{mg} / \mathrm{ml}$ streptomycin; Gibco; Thermo Fisher Scientific, Inc.) at $37^{\circ}$ in a humidified atmosphere containing $5 \% \mathrm{CO}_{2}$.

Cell transfection. miRNA mimics may enhance the regulation of endogenous miRNAs, whereas miRNA inhibitors inhibit the function of miRNA (17). The number of cells $\left(5 \times 10^{3}-1 \times 10^{6}\right.$ cells/well) depended on the volume of the plate. Transfection using miR-425-5p mimic and miR-425-5p inhibitor may upregulate and downregulate the expression level of miR-425-5p, respectively, according to the manufacturer's protocol (Table II), ACHN and 786-O cells were cultured in $96,48,24$ or 6 -well plates and treated with 5, 20, 40 or 100 pmol small interfering RNA (siRNA) using Lipofectamine ${ }^{\circledR} 2000$ (Thermo Fisher Scientific, Inc.) at $37^{\circ}$ 
Table III. Sequences used in the study.

\begin{tabular}{ll}
\hline Name & \multicolumn{1}{c}{ Sequence } \\
\hline miR-425-5p & Forward: 5'-AATGACACGATCACTCCCGTTGA-3' \\
U6 & Reverse: Universal primers (miScript SYBR-Green PCR kit) \\
& Forward: 5'-CTCGCTTCGGCAGCACA-3' \\
miR-425-5p mimic & Reverse: 5'-ACGCTTCACGAATTTGCGT-3' \\
miR-425-5p inhibitor & Forward: 5'-AAUGACACGAUCACUCCCGUUGA-3' \\
NC & Reverse: 5'-AACGGGAGUGAUCGUGUCAUUUU-3' \\
Inhibitor NC & 5'-AGGCGAAGGAUGACAAAGGGAA-3' \\
& Forward: 5'-UUCUCCGAACGUGUCACGUTT-3' \\
& Reverse: 5'-ACGUGACACGUUCGGAGAATT-3' \\
& 5'-CAGUACUUUUGUGUAGUACAA-3'
\end{tabular}

microRNA, miRNA/miR; NC, negative control.

in a humidified atmosphere containing $5 \% \mathrm{CO}_{2}$, respectively. Prior to adding DMEM, cells were incubated with Opti-MEM medium (Gibco; Thermo Fisher Scientific, Inc.) supplemented without $10 \%$ FBS and $1 \%$ glutamine for $6 \mathrm{~h}$. The transfection efficiency was analyzed using RT-qPCR. The sequences of miR-425-5p mimic, inhibitor, negative control (NC) mimic, NC inhibitor (Shanghai GenePharma Co., Ltd., Shanghai, China) are presented in Table III.

Cell counting kit-8 (CCK-8). A CCK-8 assay (Beyotime Institute of Biotechnology, Haimen, China) was used to assess the proliferative ability of 786-O and ACHN cells. Cells (5,000 cells/well) were seeded in 96-well plates and then transfected with miR-425-5p mimic, inhibitor, NC mimic or NC inhibitor (Shanghai GenePharma Co., Ltd.). In brief, a total of $10 \mu \mathrm{l}$ CCK-8 solution was added into each well and cells were incubated for $30 \mathrm{~min}$ at $37^{\circ} \mathrm{C}$ in a humidified atmosphere containing $5 \% \mathrm{CO}_{2}$. After cells were incubated for $0,24,48$ and $72 \mathrm{~h}$, cell proliferation was determined by measuring the absorbance at $450 \mathrm{~nm}$ (with $620 \mathrm{~nm}$ as the reference wavelength) using a microplate reader (Bio-Rad Laboratories, Inc., Hercules, CA, USA). The experiment was performed in triplicate.

MTT assay. MTT assay (Sigma-Aldrich; Merck KGaA, Darmstadt, Germany) was used to assess the viability of 786-O and ACHN cells. A total of 5,000 cells/well were seeded in 96-well plates. A total of 3 days after transfection, $20 \mu \mathrm{l}$ MTT ( $5 \mathrm{mg} / \mathrm{ml}$; Sigma-Aldrich; Merck KGaA) was added into each well plate for $4 \mathrm{~h}$ at $37^{\circ} \mathrm{C}$. After removing supernatant, $100 \mu \mathrm{l}$ dimethyl sulfoxide (DMSO; Sigma-Aldrich; Merck KGaA) was added into each well. The cells were then agitated using a shaker (TSB-108; Qilinbeier, Jiangsu, China) at $0.16 \mathrm{~g} / \mathrm{min}$ for $10 \mathrm{~min}$ in dark at room temperature. The viability was evaluated at a wavelength of $595 \mathrm{~nm}$ (with $620 \mathrm{~nm}$ as the reference wavelength) using a microplate reader (Bio-Rad Laboratories, Inc.). The experiment was performed in triplicate.

Wound healing assay. The wound healing assay was used to assess the migratory ability of the ACHN and 786-O cells. A total of $2 \times 10^{4}$ cells were seeded in each well of a 96-well plate.
Prior to transfection, cells were starved for $24 \mathrm{~h}$. Then, cells were transfected with miR-425-5p mimic, inhibitor, NC mimic or NC inhibitor as aforementioned. After transfection, cells were cultured in serum and antibiotics-free media at $37^{\circ} \mathrm{C}$ for $24 \mathrm{~h}$. Next, wounds were inflicted by dragging a sterile pipette tip. Images were captured using a digital camera system at 0,12 and $24 \mathrm{~h}$ at $37^{\circ} \mathrm{C}$. The experiment was performed in triplicate.

Transwell assay. The migratory and invasive abilities of the ACHN and 786-O cells were assessed using 24-well Transwell chambers (BD Biosciences, Franklin Lakes, NJ, USA) with $8 \mu \mathrm{m}$ pore size inserts. At $24 \mathrm{~h}$ post-transfection, a total of $\sim 3 \times 10^{4}$ cells were plated in each upper chamber. The lower chamber of the Transwell contained $600 \mu \mathrm{l}$ medium (DMEM or RPMI-1640) supplemented with $10 \%$ FBS and $1 \%$ glutamine. For the invasion assay, Matrigel-coated Transwell chambers, according to the manufacturer's instructions. At $48 \mathrm{~h}$, cells were fixed using $0.1 \%$ paraformaldehyde for $25 \mathrm{~min}$ and stained using $4 \%$ crystal violet stain for $25 \mathrm{~min}$ at room temperature. Images were captured using a digital camera. The experiment was performed in triplicate. Cells were counted in 4 randomly selected field of view using a light microscope at magnification, x100.

Flow cytometry. Flow cytometry was used to assess the apoptotic rate in ACHN and 786-O cells. A total of $1 \times 10^{6}$ cells were plated in a 6-well plate. At $24 \mathrm{~h}$, cells were transfected with miR-425-5p mimic, inhibitor, NC mimic or NC inhibitor as aforementioned. At $48 \mathrm{~h}$ post-transfection, cells were harvested and washed using ice-cold PBS. Next, cells were stained with $5 \mu$ l Annexin V-fluorescein isothiocyanate (FITC; Invitrogen; Thermo Fisher Scientific, Inc.) and propidium iodide (PI; Invitrogen; Thermo Fisher Scientific, Inc.), according to the manufacturer's instructions. The apoptotic rate was evaluated using a flow cytometer (EPICS, Xl-4, Beckman Coulter, Inc., Brea, CA, USA). FlowJo software version 7.6.1 (FlowJo LLC, Ashland, OR, USA) was used for analysis of the data. The experiment was performed in triplicate.

Statistical analysis. Data were analyzed using SPSS software version 23.0 (IBM Corp., Armonk, NY, USA). Data are 

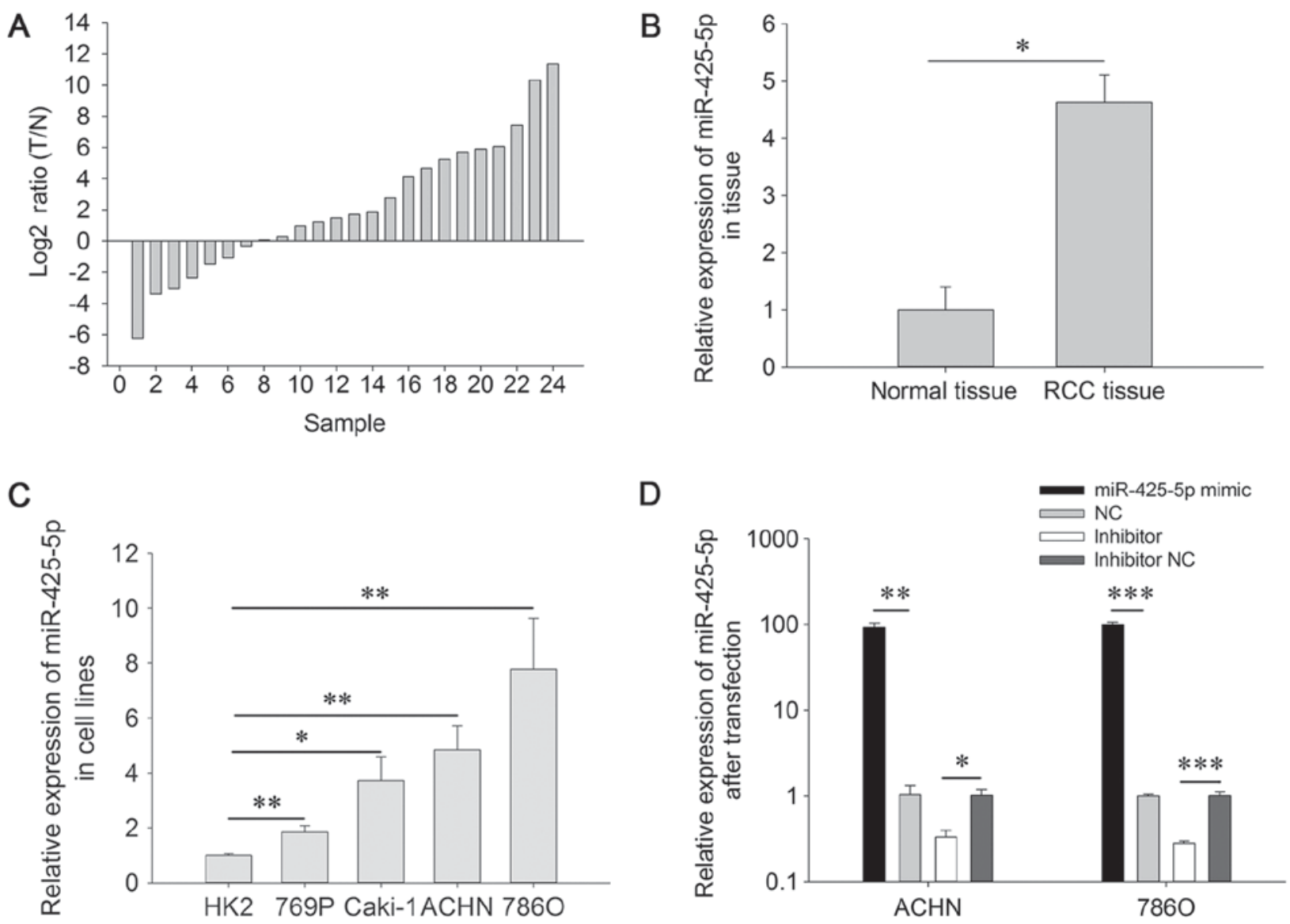

Figure 1. The relative expression of miR-425-5p in 24 RCC tissues and cell lines. (A) $\log _{2}$ ratios of miR-425-5p expression in 24 RCC and paired adjacent normal tissues. (B) The relative expression of miR-425-5p in RCC and normal tissues. (C) The relative expression of miR-425-5p in RCC cell lines. (D) The relative expression of miR-425-5p in response to treatment with miR-425-5p mimic, NC, miR-425-5p inhibitor and inhibitor NC in ACHN and 786O cells. ${ }^{*} \mathrm{P}<0.05,{ }^{* *} \mathrm{P}<0.01,{ }^{* * *} \mathrm{P}<0.001$. RCC, renal cell carcinoma; NC, negative control; $\mathrm{T}, \mathrm{RCC}$ tissues; $\mathrm{N}$, paired adjacent normal tissues; microRNA, miRNA/miR.

expressed as the mean \pm standard deviation. The expression level of miR-425-5p in tissues was analyzed using a paired Student's t-test. The expression level of miR-425-5p in RCC cell lines was evaluated using one-way analysis of variance followed by Bonferroni's post hoc test. Student's t-test was used to analyze the results of between two groups. $\mathrm{P}<0.05$ was considered to indicate a statistically significant difference.

\section{Results}

The expression level of miR-425-5p is upregulated in $R C C$ tissues and cell lines. RT-qPCR was performed to detect the expression of miR-425-5p in RCC tissues and cell lines. Fig. 1A presents the ratio of miR-425-5p [ $\log _{2}$ ratio (Tumor tissue/Normal tissue)] in 24 paired RCC and adjacent normal tissue specimens. As demonstrated in Fig. 1B, the expression level of miR-425-5p was significantly increased in RCC tissues (4.628 \pm 0.483$)$ compared with that in adjacent normal tissues $(1.000 \pm 0.399 ; \mathrm{P}=0.020)$. The expression levels of miR-425-5p in RCC cell lines were significantly increased compared with those in normal kidney cells $(\mathrm{P}<0.01)$. Therefore, these results suggest that miR-425-5p may act as an oncogene in RCC.

Cell transfection efficiency. RT-qPCR was performed to detect the expression level of miR-425-5p after transfection. At $24 \mathrm{~h}$ post-transfection, the expression levels of miR-425-5p were increased by 99.008 -fold in 7860 cells $(\mathrm{P}<0.001$; Fig. 1D) and 92.137-fold in ACHN cells ( $P=0.003$; Fig. 1D) in response to miR-425-5p mimic compared with $\mathrm{NC}$ mimic. At $24 \mathrm{~h}$ post-transfection, the expression levels of miR-425-5p were increased by 0.281 ( 7860 cells; $\mathrm{P}<0.001)$ and 0.330 -fold (ACHN cells; $\mathrm{P}=0.037$ ) in response to $\mathrm{miR}-425-5 \mathrm{p}$ inhibitor compared with NC inhibitor.

Upregulation or downregulation of $\mathrm{miR}-425-5 \mathrm{p}$ regulates the viability of ACHN and 7860 cells. MTT assay was used to evaluate cell viability. As presented in Fig. 2, the relative viability of ACHN cells transfected with the miR-425-5p mimic was increased compared with that in NC mimic group $(\mathrm{P}=0.002)$. The relative viability of 7860 cells transfected with miR-425-5p mimic was increased compared with that in NC mimic group $(\mathrm{P}=0.002)$. Additionally, the relative viability of ACHN cells transfected with the miR-425-5p inhibitor was decreased compared with that in the $\mathrm{NC}$ inhibitor group $(\mathrm{P}=0.048$; Fig. 2A). These results were consistent in $786 \mathrm{O}$ cells $(\mathrm{P}=0.038$; Fig. $2 \mathrm{~B})$.

Upregulation or downregulation of $\mathrm{miR}-425-5 \mathrm{p}$ regulates the proliferation of ACHN and 7860 cells. CCK-8 assay was used to assess the proliferative ability of ACHN and 7860 cells. At 24,48 and $72 \mathrm{~h}$ post-transfection, the viability of $\mathrm{ACHN}$ cells was upregulated by $12.877(\mathrm{P}=0.009), 19.068(\mathrm{P}=0.003)$ 
A

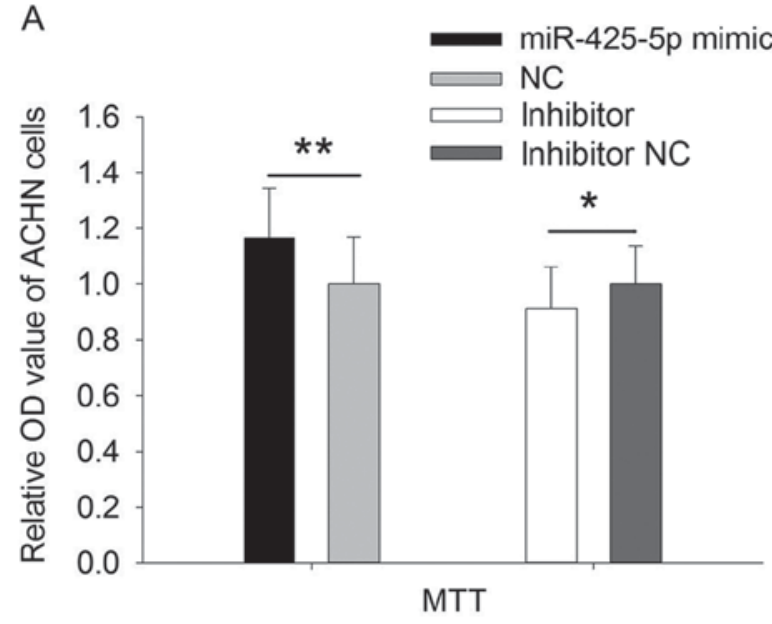

$\begin{aligned} \mathrm{C} \quad & \because \mathrm{miR}-425-5 \mathrm{p} \text { mimic } \\ & \longrightarrow \mathrm{NC}\end{aligned}$

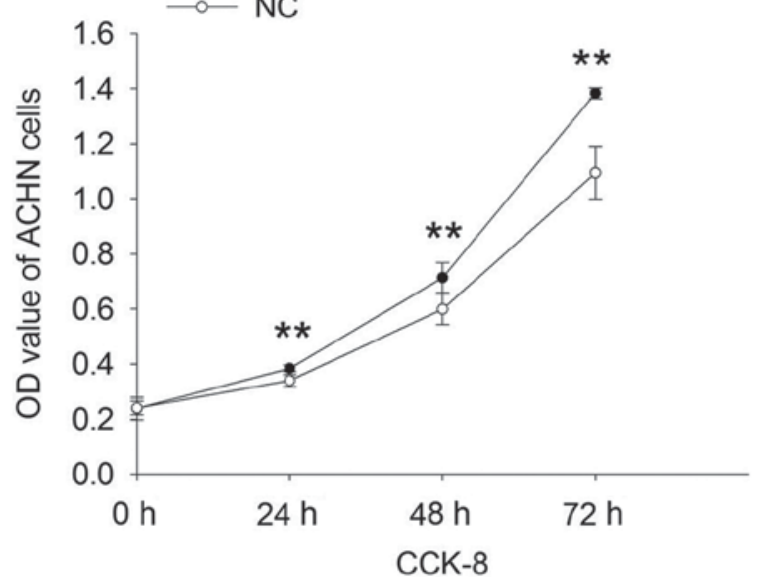

E

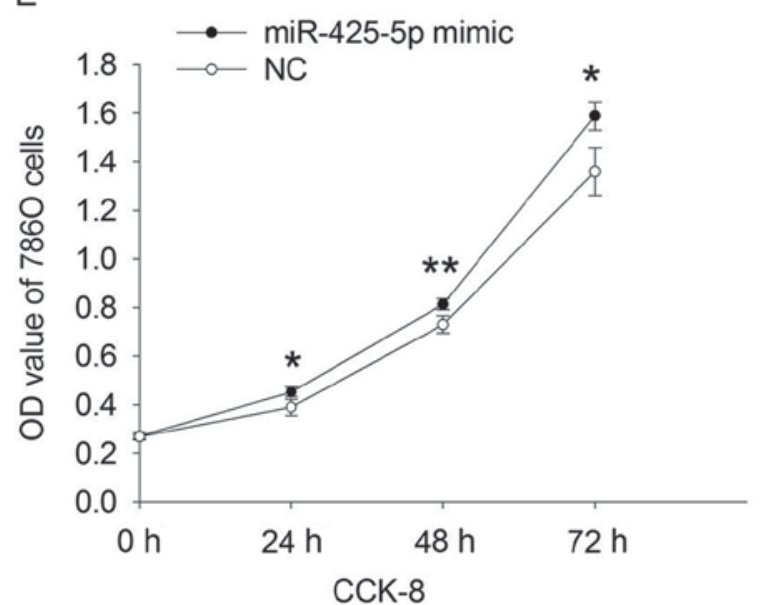

B
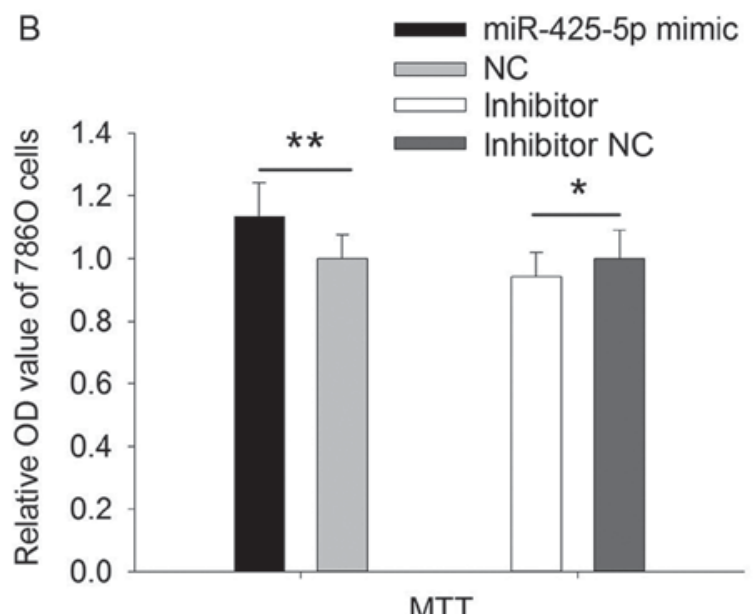

D

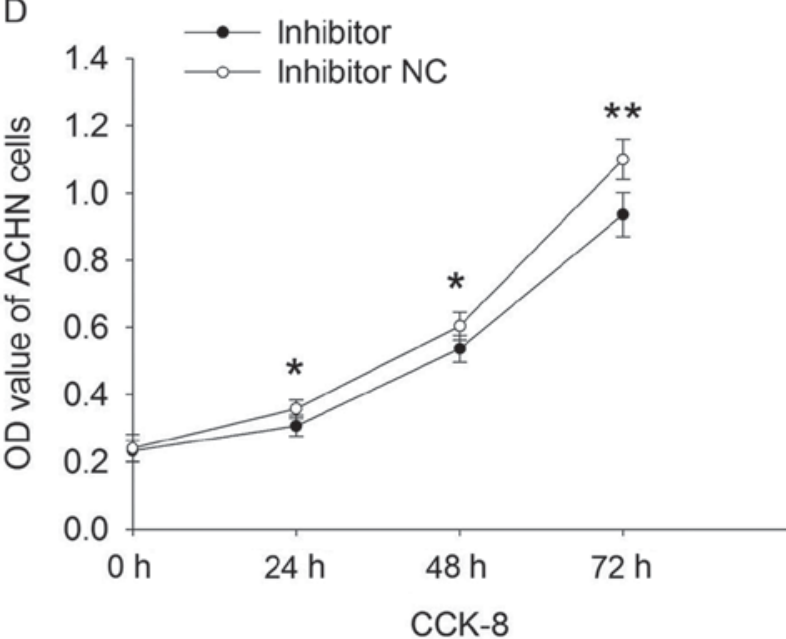

F

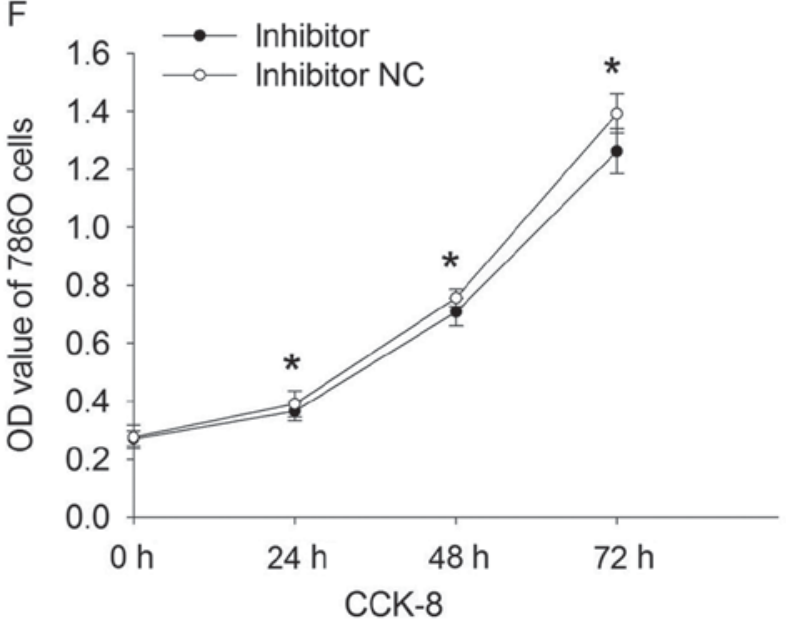

Figure 2. Cell viability and proliferation in response to treatment with miR-425-5p mimic, NC mimic, miR-425-5p inhibitor and NC inhibitor in ACHN and 7860 cells. MTT assay was used to evaluate the viability abilities of (A) ACHN and (B) 786O cells transfected with miR-425-5p mimic, NC mimic, miR-425-5pinhibitor or NC inhibitor. CCK-8 assay was used to assess the proliferative abilities of ACHN transfected with (C) miR-425-5pmimic or NC mimic and (D) miR-425-5p inhibitor or NC inhibitor. CCK-8 assay was used to assess the proliferative abilities of 786O transfected with (E) miR-425-5pmimic or NC mimic and (F) miR-425-5p inhibitor or NC inhibitor. ${ }^{*} \mathrm{P}<0.05,{ }^{* *} \mathrm{P}<0.01$. NC, negative control; microRNA, miRNA/miR; CCK-8, Cell Counting kit-8.

and $26.441 \%(\mathrm{P}=0.002)$ in response to $\mathrm{miR}-425-5 \mathrm{p}$ mimic compared with that in $\mathrm{NC}$ mimic group (Fig. 2C), whereas the viability of ACHN cells was downregulated by 14.183 $(\mathrm{P}=0.014), 11.483(\mathrm{P}=0.040)$ and $14.948 \%$ ( $\mathrm{P}=0.009$; Fig. 2D) in response to miR-425-5p inhibitor compared with that in
NC inhibitor group. Additionally, the viability of 7860 cells was upregulated by $15.991(\mathrm{P}=0.034), 11.485(\mathrm{P}=0.006)$ and $16.863 \%(\mathrm{P}=0.013)$ in response to $\mathrm{miR}-425-5 \mathrm{p}$ mimic compared with that in NC mimic group (Fig. 2E) during those time points whereas the viability of 7860 cells was decreased by 


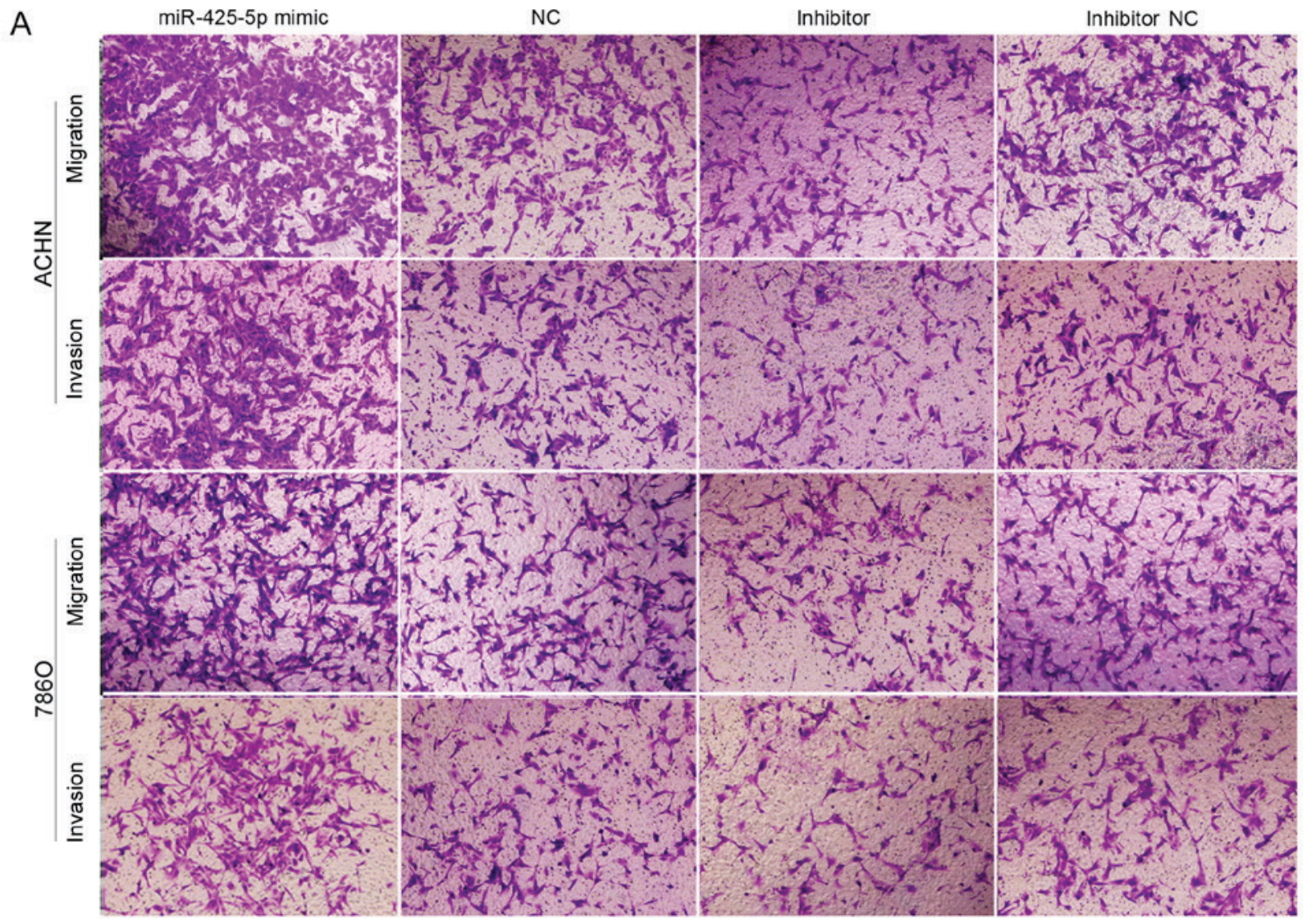

B

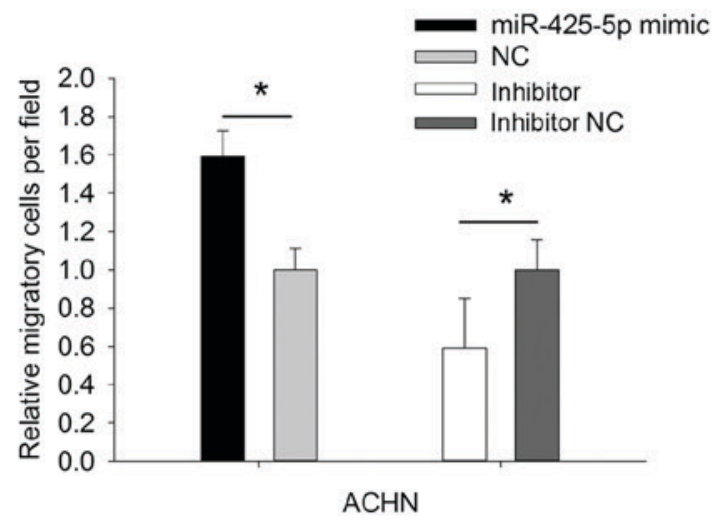

D

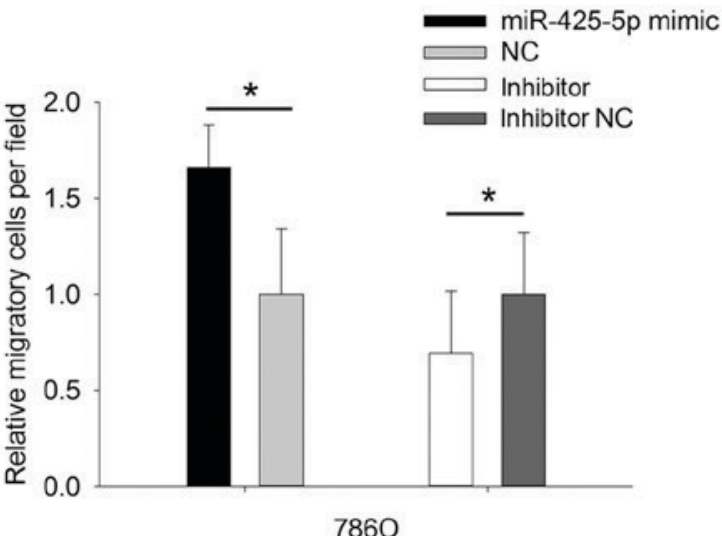

C

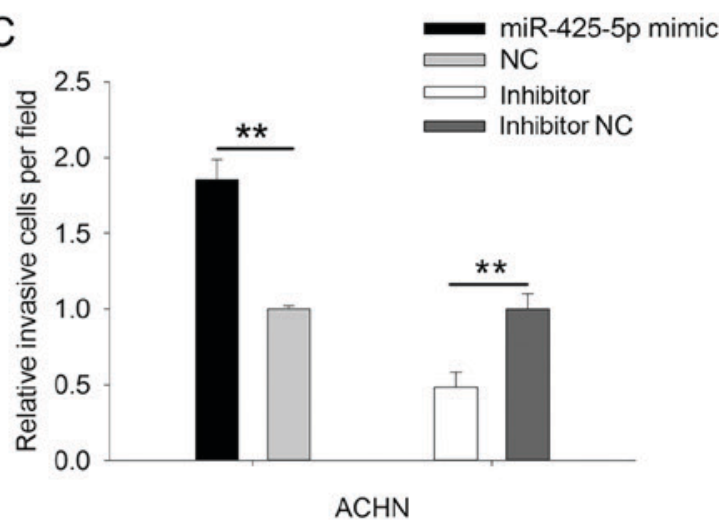

$E$

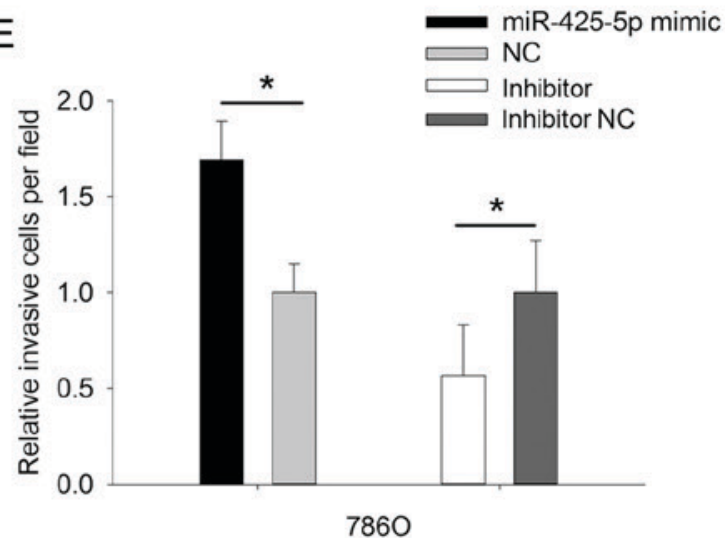

Figure 3. miR-425-5p regulates the migratory and invasive abilities of ACHN and $786 \mathrm{O}$ cells. (A) Representative images of migration and invasion assays in ACHN and 7860 cells. Magnification, x100. Quantification of relative (B) migration and (C) invasion in ACHN cells transfected with miR-425-5p mimic, NC mimic, miR-425-5p inhibitor or NC inhibitor. Quantification of relative (D) migration and (E) invasion in $786 \mathrm{O}$ cells transfected with miR-425-5p mimic, NC mimic, miR-425-5p inhibitor or NC inhibitor. ${ }^{*} \mathrm{P}<0.05,{ }^{* *} \mathrm{P}<0.01$. NC, negative control; microRNA, miRNA/miR. 
A

A $\quad$ ACHN

\begin{tabular}{ll}
\multicolumn{3}{c}{7860} \\
\cline { 2 - 3 }
\end{tabular}

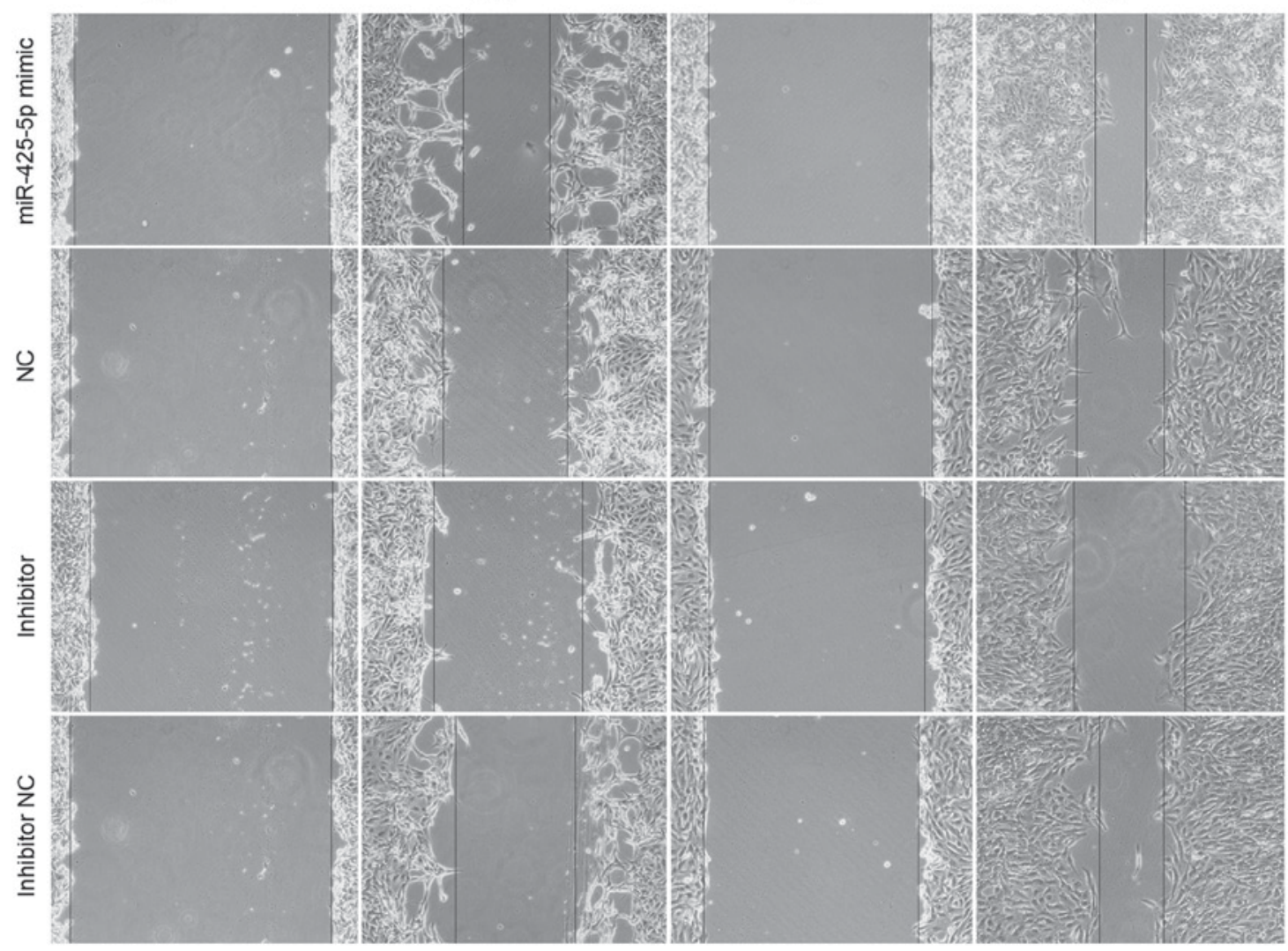

B

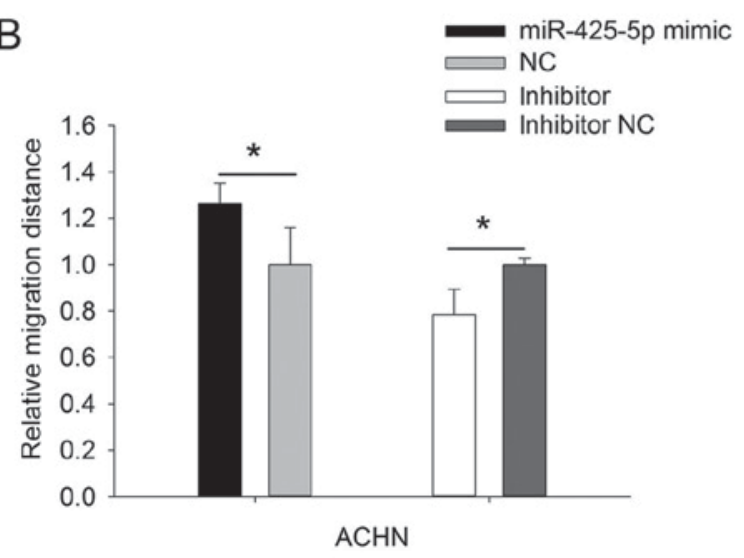

C

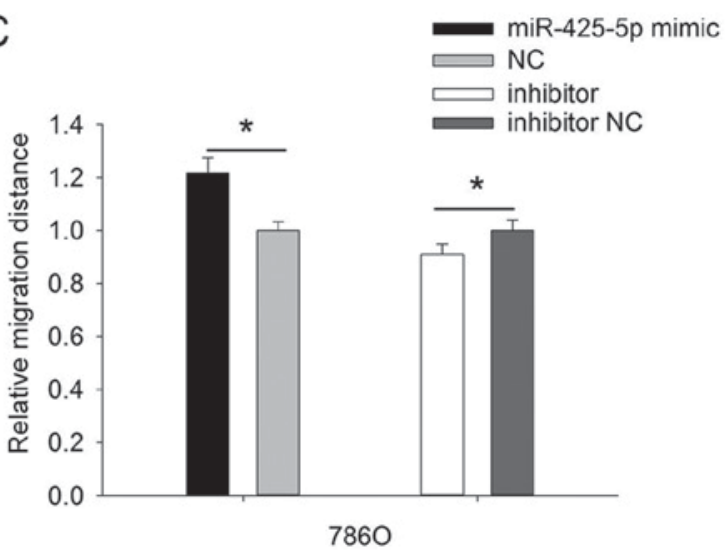

Figure 4. The migration of ACHN and 7860 was evaluated using a wound scratch assay. Magnification, x100. (A) Representative images of migration in ACHN and 7860 cells. Quantification of relative migration in (B) ACHN and (C) 7860 cells. ${ }^{*} \mathrm{P}<0.05$. NC, negative control; microRNA, miRNA/miR.

$6.299(\mathrm{P}=0.050), 4.443(\mathrm{P}=0.013), 9.344 \%$ ( $\mathrm{P}=0.013$; Fig. $2 \mathrm{~F})$ in response to miR-425-5p inhibitor compared with that in $\mathrm{NC}$ inhibitor group. Therefore, upregulation or downregulation of miR-425-5p may promote or inhibit, respectively, the proliferative ability of ACHN and 7860 cells.

miR-425-5p regulates migration and invasion in ACHN and 7860 cells. The migratory and invasive abilities of ACHN and 7860 cells were evaluated using Transwell (Fig. 3A-E) and wound scratch assays (Fig. 4A-C). The results demonstrated that the migratory ability of the ACHN cells was upregulated $(\mathrm{P}=0.039$; Fig. $3 \mathrm{~B})$ in the miR-425-5p mimic group compared with that in the NC mimic group. However, their migratory ability was by $40.738 \%(\mathrm{P}=0.048)$ in response to treatment with miR-425-5p inhibitor (Fig. 3B). Additionally, the invasive ability of the ACHN cells was upregulated $(\mathrm{P}=0.001)$ in the miR-425-5p mimic group, whereas the invasive ability of the ACHN cells was downregulated $(\mathrm{P}=0.008)$ in $\mathrm{miR}-425-5 \mathrm{p}$ inhibitor group (Fig. 3C). For the 7860 cells, those results were consistent with the above results of ACHN cells $(\mathrm{P}<0.05)$.

The results of the wound healing assay (Fig. 4A-C) demonstrated that the migratory ability of the ACHN cells was upregulated $(\mathrm{P}=0.025)$ in the $\mathrm{miR}-425-5 \mathrm{p}$ mimic group, whereas their migratory ability was downregulated $(\mathrm{P}=0.048)$ in the 

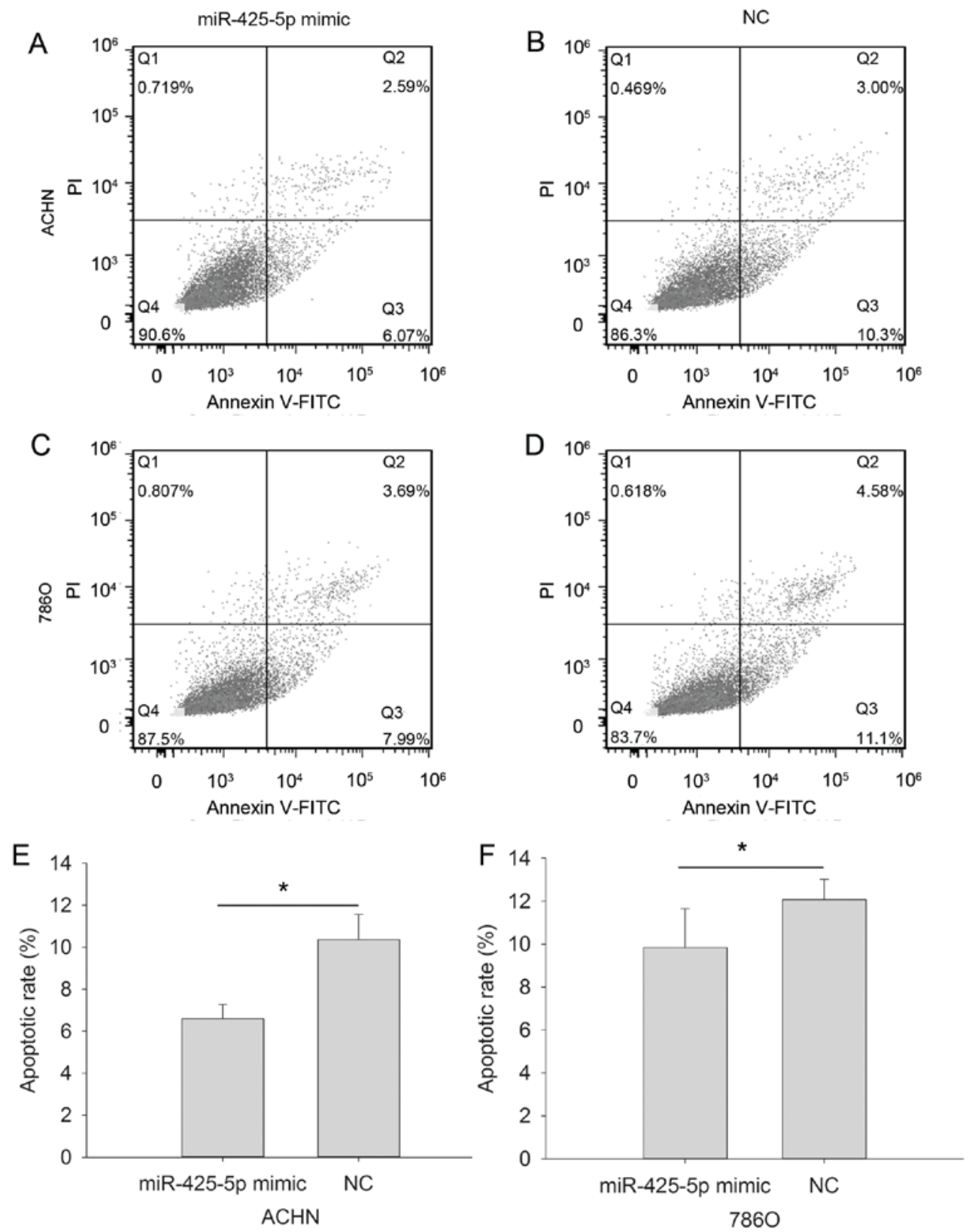

Figure 5. Upregulation of miR-425-5p inhibits early apoptosis in ACHN and $786 \mathrm{O}$ cells. Representative dot plots of Annexin V/PI staining in ACHN cells treated with (A) miR-425-5p mimic or (B) NC mimic. Representative dot plots of Annexin V/PI staining in 786O cells treated with (C) miR-425-5p mimic or (D) NC mimic. Quantification of early apoptosis in (E) ACHN and (F) 7860 cells transfected with miR-425-5p mimic or NC mimic. "P $<0.05$. NC, negative control; microRNA, miRNA/miR; FITC, fluorescein isothiocyanate; PI, propidium iodide.

miR-425-5p inhibitor group (Fig. 4B). Those results in $786 \mathrm{O}$ cells were consistent with the above results in ACHN cells $(\mathrm{P}<0.05)$.

Upregulation of miR-425-5p inhibits apoptosis in ACHN and 7860 cells. Early apoptotic rate was determined using flow cytometry (Fig. 5A-F). The results demonstrated that the early apoptotic rate of ACHN cells transfected with the miR-425-5p mimic was decreased compared with that of the NC mimic group $(6.593 \pm 0.671 \%$ vs. $10.360 \pm 1.211 \%$; $\mathrm{P}=0.015$; Fig. $5 \mathrm{E}$. The apoptotic rate of the $786 \mathrm{O}$ cells in response to miR-425-5p mimic and $\mathrm{NC}$ was observed to be $9.843 \pm 1.807 \%$ vs. $12.067 \pm 0.950 \%$, respectively $(\mathrm{P}=0.046$; Fig. $5 \mathrm{~F}$ ). However, no differences in early apoptotic rate were observed between the inhibitor and $\mathrm{NC}$ inhibitor groups for $786 \mathrm{O}$ and ACHN cells were observed (data not shown).

\section{Discussion}

miRNAs are a class of endogenous non-coding RNAs that serve important functions in tumorigenesis. However, the underlying molecular mechanism remains unclear (18). Numerous studies have demonstrated that miRNAs may function as oncogenes or tumor suppressors and may serve an important biological role in various tumor types (19).

Sun et al (10) demonstrated that miR-425-5p is upregulated in cervical cancer tissues compared with matched non-cancerous tissues. Additionally, miR-425-5p is upregulated in the serum of 
patients with cervical cancer, which suggests that it may act as a potential biomarker in cervical cancer. Zhang et al (9) demonstrated that miR-425-5p is upregulated in gastric cancer cell lines and may regulate cell migration and invasion in vitro. These results were also confirmed by Peng et al (20). Wang et al (21) revealed that miR-425 may drive tumor formation and growth, and promote the progression of lung cancer. Furthermore, Di Leva et al (22) demonstrated that miR-425 may promote the expression of epithelial markers by targeting SATB homeobox 1, cyclin 2 (CCND2) and Fascin actin-bundling protein 1 in aggressive breast cancer cells. Recently, it was reported that miR-425-5p may regulate chemoresistance via programmed cell death 10 in colorectal cancer cells lines (23). A study by Fang et al (24) indicated an upregulation of miR-425-5p in hepatocellular carcinoma tissues, which was associated with poor clinicopathological characteristics and prognosis. Furthermore, miR-425-5p may promote metastasis via inhibiting suppressor of cancer cell invasion (SCAI)-mediated dysregulation of the transcriptional regulation of integrin $\beta 1$-Focal Adhesion Kinase 1 (ITGB1-Fak), SRC proto-oncogene-Ras homolog gene family member A (Src-RhoA)/cell division cycle 42 (CDC42), phosphatase and tensin homolog (PTEN/AKT)/Murine thymoma viral (v-Akt) oncogene homolog and TIMP metallopeptidase inhibitor 2-zinc-dependent matrix metalloproteinases 2/zinc-dependent matrix metalloproteinases 9 (TIMP2-MMP2/MMP9) signaling pathways (24).

miR-425-5p serves an important role in various diseases. Di Pietro et al (25) demonstrated that miR-425-5p was significantly downregulated in traumatic brain injury at early timepoints and may be used as a diagnostic biomarker. A study on Alzheimer's disease (AD) demonstrated that miR-339 and miR-425 may be used as potential diagnostic biomarkers for AD. Additionally, miRNAs may inhibit the $\beta$-secretase 1 (BACE1) protein expression level and are involved in the pathogenesis of AD (26). Gao et al (27) found that the over-expression of miR-425-5p may reverse the $\mathrm{NaAsO} 2$-induced anti-angiogenesis by directly targeting cerebral cavernous malformation 3 .

However, there are several limitations. Firstly, due to the long storage of specimens and the absence of some clinical data, the present study was unable to analyze the association between the expression of mir-425-5p and clinical data. Secondly, further experiments are required to confirm the results of the present study. For example, it is recommended to block cell proliferation using cell cycle inhibitors prior to analyzing the effect on cell migration instead of hunger, which may strengthen the results of the present study. Additionally, although miR-425-5p expression was increased by $\sim 100$-fold in $\mathrm{RCC}$ cells in response to $\mathrm{miR}-425-5 \mathrm{p}$ mimic in vitro, the increase was lower (5-fold) in RCC tissues compared to controls. The regulation of $\mathrm{miR}-425-5 \mathrm{p}$ expression may be more complex in vivo than in vitro. Although CCK-8 assay was used to evaluate the proliferative ability of RCC cells, further assays including 5-Bromo-2-deoxyUridine (BrdU) and 5-Ethynyl-2'-deoxyuridine (EdU) assays (28), are required to confirm the results of the present study.

The results of the present study demonstrated that the expression levels of miR-425-5p were upregulated in RCC cell lines and tissues compared with controls. Furthermore, the results of functional assays suggested that miR-425-5p may function as an oncogene in RCC. Therefore, the molecular mechanisms underlying the function of miR-425-5p in RCC require further investigation.

\section{Acknowledgements}

Not applicable.

\section{Funding}

The present study was supported by the National Natural Science Foundation of China (grant no. 81101922), the Science and Technology Development Fund Project of Shenzhen (grant nos. JCYJ20150403091443329 and JCYJ20170307111334308), the 'San-ming' Project of Medicine in Shenzhen and the fund of Guangdong Key Medical Subject.

\section{Availability of data and materials}

The data sets generated during the present study are available from the corresponding author on reasonable request.

\section{Authors' contributions}

YQL conceived and designed the experiments. JQ, YWL, XP, YLL, TH, CL, LiaZ and LiwZ performed the experiments, analyzed the data and drafted the paper. SS, YD, LT, YH, XW, ZC, FZ, JY and LN assisted in collecting tissue specimens and writing the manuscript. All authors have read and approved this manuscript.

\section{Ethics approval and consent to participate}

All patients signed informed consent forms prior to the initiation of the present study. The present study was approved by the Ethical Review Committee of the Peking University Shenzhen Hospital and complied with the Declaration of Helsinki.

\section{Consent for publication}

All patients provided their consent for data sharing and the publication of any associated images.

\section{Competing interests}

The authors declare that they have no competing interests.

\section{References}

1. Ljungberg B, Bensalah K, Canfield S, Dabestani S, Hofmann F, Hora M, Kuczyk MA, Lam T, Marconi L, Merseburger AS, et al: EAU guidelines on renal cell carcinoma: 2014 update. Eur Urol 67: 913-924, 2015.

2. Udager AM and Mehra R: Morphologic, molecular and taxonomic evolution of renal cell carcinoma: A conceptual perspective with emphasis on updates to the 2016 world health organization classification. Arch Pathol Lab Med 140: 1026-1037, 2016.

3. Gnarra JR, Tory K, Weng Y, Schmidt L, Wei MH,Li H,Latif F, Liu S, Chen F,DuhFM, et al: Mutations of the VHL tumour suppressor gene in renal carcinoma. Nat Genet 7: 85-90, 1994

4. Varela I, Tarpey P, Raine K, Huang D, Ong CK, Stephens P, Davies H, Jones $\mathrm{D}$, Lin ML, Teague J, et al: Exome sequencing identifies frequent mutation of the SWI/SNF complex gene PBRM1 in renal carcinoma. Nature 469: 539-542, 2011. 
5. Bartel DP: MicroRNAs: Target recognition and regulatory functions. Cell 136: 215-233, 2009.

6. Li G, Chong T, Xiang X, Yang J and Li H: Downregulation of microRNA-15a suppresses the proliferation and invasion of renal cell carcinoma via direct targeting of eIF4E. Oncol Rep 38 : 1995-2002, 2017.

7. Jin L, Li Y, Liu J, Yang S, Gui Y, Mao X, Nie G and Lai Y: Tumor suppressor miR-149-5p is associated with cellular migration, proliferation and apoptosis in renal cell carcinoma. Mol Med Rep 13: 5386-5392, 2016.

8. Li Y, Chen D, Jin LU, Liu J, Li Y, Su Z, Qi Z, Shi M, Jiang Z and Yang S: Oncogenic microRNA-142-3p is associated with cellular migration, proliferation and apoptosis in renal cell carcinoma. Oncol Lett 11: 1235-1241, 2016.

9. Zhang Z, Li Y, Fan L, Zhao Q, Tan B, Li Z and Zang A: microRNA-425-5p is upregulated in human gastric cancer and contributes to invasion and metastasis in vitro and in vivo. Exp Ther Med 9: 1617-1622, 2015.

10. Sun L, Jiang R, Li J, Wang B, Ma C, Lv Y and Mu N: MicoRNA-425-5p is a potential prognostic biomarker for cervical cancer. Ann Clin Biochem 54: 127-133, 2017.

11. Vaira V, Roncalli M, Carnaghi C, Faversani A, Maggioni M Augello C, Rimassa L, Pressiani T, Spagnuolo G, Di Tommaso L, et al: MicroRNA-425-3p predicts response to sorafenib therapy in patients with hepatocellular carcinoma. Liver Int 35: 1077-1086, 2015.

12. Hao JF, Ren KM, Bai JX, Wang SN, Shao B, Cao N and Li X: Identification of potential biomarkers for clear cell renal cell carcinoma based on microRNA-mRNA pathway relationships. J Cancer Res Ther 10 Suppl: C167-C177, 2014.

13. Ge YZ, Xin H, Lu TZ, Xu Z, Yu P, Zhao YC, Li MH, Zhao Y, Zhong B, Xu X, et al: MicroRNA expression profiles predict clinical phenotypes and prognosis in chromophobe renal cell carcinoma. Sci Rep 5: 10328, 2015.

14. Wang X, Liu Y, Cao G, Zhang X, Xu H, Xu H and Wang J: Expression of the EphA1 protein is associated with Fuhrman nuclear grade in clear cell renal cell carcinomas. Int J Clin Exp Pathol 8: 6821-6827, 2015.

15. Moch H, Artibani W, Delahunt B, Ficarra V, Knuechel R, Montorsi F, Patard JJ, Stief CG, Sulser T and Wild PJ: Reassessing the current UICC/AJCC TNM staging for renal cell carcinoma. Eur Urol 56: 636-643, 2009.

16. Livak KJ and Schmittgen TD: Analysis of relative gene expression data using real-time quantitative PCR and the 2(-Delta Delta C(T)) method. Methods 25: 402-408, 2001.

17. Qian H, Deng X, Huang ZW, Wei J, Ding CH, Feng RX, Zeng X, Chen YX, Ding J, Qiu L, et al: An HNF1 $\alpha$-regulated feedback circuit modulates hepatic fibrogenesis via the crosstalk between hepatocytes and hepatic stellate cells. Cell Res 25: 930-945, 2015

18. Lee YS and Dutta A: MicroRNAs in cancer. Annu Rev Pathol 4 199-227, 2009.
19. Inui M, Martello G and Piccolo S: MicroRNA control of signal transduction. Nat Rev Mol Cell Biol 11: 252-263, 2010.

20. Peng WZ, Ma R, Wang F, Yu J and Liu ZB: Role of miR-191/425 cluster in tumorigenesis and diagnosis of gastric cancer. Int J Mol Sci 15: 4031-4048, 2014.

21. Wang J, Li Z, Ge Q, Wu W, Zhu Q, Luo J and Chen L: Characterization of microRNA transcriptome in tumor, adjacent and normal tissues of lung squamous cell carcinoma. J Thorac Cardiovasc Surg 149: 1404-1414 e1404, 2015

22. Di Leva G, Piovan C, Gasparini P, Ngankeu A, Taccioli C, Briskin D, Cheung DG, Bolon B, Anderlucci L, Alder H, et al: Estrogen mediated-activation of miR-191/425 cluster modulates tumorigenicity of breast cancer cells depending on estrogen receptor status. PLoS Genet 9: e1003311, 2013.

23. Zhang Y, Hu X, Miao X, Zhu K, Cui S, Meng Q, Sun J and Wang T: MicroRNA-425-5p regulates chemoresistance in colorectal cancer cells via regulation of Programmed Cell Death 10. J Cell Mol Med 20: 360-369, 2016.

24. Fang F, Song T, Zhang T, Cui Y, Zhang G and Xiong Q: MiR-425-5p promotes invasion and metastasis of hepatocellular carcinoma cells through SCAI-mediated dysregulation of multiple signaling pathways. Oncotarget 8: 31745-31757, 2017

25. Di Pietro V, Ragusa M, Davies D, Su Z, Hazeldine J, Lazzarino G, Hill LJ, Crombie N, Foster M and Purrello M: MicroRNAs as novel biomarkers for the diagnosis and prognosis of mild and severe traumatic brain injury. J Neurotrauma 34: 1948-1956, 2017.

26. Ren RJ, Zhang YF, Dammer EB, Zhou Y, Wang LL, Liu XH, Feng BL, Jiang GX, Chen SD, Wang G and Cheng Q: Peripheral blood microrna expression profiles in alzheimer's disease: screening, validation, association with clinical phenotype and implications for molecular mechanism. Mol Neurobiol 53: 5772-5781, 2016.

27. Gao Y, Yin Y, Xing X, Zhao Z, Lu Y, Sun Y, Zhuang Z, Wang M, Ji W and He Y: Arsenic-induced anti-angiogenesis via miR-425-5p-regulated CCM3. Toxicol Lett 254: 22-31, 2016.

28. Buck SB, Bradford J, Gee KR, Agnew BJ, Clarke ST and Salic A: Detection of $\mathrm{S}$-phase cell cycle progression using 5-ethynyl-2'-deoxyuridine incorporation with click chemistry, an alternative to using 5-bromo-2'-deoxyuridine antibodies. Biotechniques 44: 927-929, 2008.

This work is licensed under a Creative Commons Attribution-NonCommercial-NoDerivatives 4.0 International (CC BY-NC-ND 4.0) License. 